Illingworth, M, MacLean, M and Wiggs, L

Maternal mind-mindedness: stability over time and consistency across relationships

Illingworth, M, MacLean, M and Wiggs, L (2016) Maternal mind-mindedness: stability over time and consistency across relationships. European Journal of Developmental Psychology, 13 (4). pp. 488-503.

doi: $10.1080 / 17405629.2015 .1115342$

This version is available: https://radar.brookes.ac.uk/radar/items/1e5b13f8-8336-45a9-85f5-1f6ea6832c0c/1/

Available on RADAR: December 2016

Copyright (C) and Moral Rights are retained by the author(s) and/ or other copyright owners. A copy can be downloaded for personal non-commercial research or study, without prior permission or charge. This item cannot be reproduced or quoted extensively from without first obtaining permission in writing from the copyright holder(s). The content must not be changed in any way or sold commercially in any format or medium without the formal permission of the copyright holders.

This document is the postprint version of the journal article. Some differences between the published version and this version may remain and you are advised to consult the published version if you wish to cite from it. 
Mind-mindedness: Stability and consistency

\section{Maternal mind-mindedness: Stability over time and consistency across relationships}

Gaby Illingworth*, Morag MacLean, Luci Wiggs

\section{Department of Psychology, Social Work \& Public Health, Oxford Brookes University, UK}

This is an authors' final version (pre-final revision) of a paper subsequently published as: Illingworth, G., MacLean, M., \& Wiggs, L. (2016). Maternal mind-mindedness: stability over time and consistency across relationships. European Journal of Developmental Psychology, 13(4) 488-503 and online at DOI:10.1080/17405629.2015.1115342

*Correspondence should be addressed to Gaby Illingworth, Nuffield Department of Clinical Neurosciences, University of Oxford, Oxford Molecular Pathology Institute, South Parks Road, Oxford, OX1 3RE (e-mail: gaby.illingworth@nden.ox.ac.uk)

This research was supported by an Economic and Social Research Council studentship to the first author. We would like to thank Clea Desebrock for help with coding and all the families for their generous participation. 


\title{
Maternal mind-mindedness: Stability over time and consistency across relationships
}

\begin{abstract}
Maternal mind-mindedness has been described both as a cognitive-behavioural trait and as a relational construct. This study assessed stability over time and consistency across relationships of maternal mind-mindedness in relation to preschool and primary school siblings and compared representational and interactional mind-mindedness. Mothers with two children between $2 \frac{1}{2}$ and 10 years were assessed twice, nine months apart $(N=32$ at Time 1 ; $N=30$ at Time 2). Representational mind-mindedness for a partner/friend was also assessed twice. Mothers' representational mind-mindedness showed temporal stability but was inconsistent across relationships with two children and a partner/friend. Conversely, mothers' interactional mind-mindedness was stable and highly consistent across relationships with two children. This supports the possibility that mothers' interactional mind-mindedness is traitlike, while findings are equivocal for representational mind-mindedness. Representational and interactional mind-mindedness were unrelated in this preliminary study, suggesting that these measures of maternal mind-mindedness were not equivalent for this age group.
\end{abstract}




\section{Introduction}

Mind-mindedness has been defined as a parent's proclivity "to treat her infant as an individual with a mind rather than merely as a creature with needs that must be satisfied" (Meins, Fernyhough, Fradley, \& Tuckey, 2001, p. 638). Mothers vary greatly in their levels of maternal mind-mindedness, assessed by whether mothers describe their children with reference to their mental attributes (Meins, Fernyhough, Russell, \& Clark-Carter, 1998; Meins et al., 2003) or whether they use appropriate mind-related comments when interacting with their children (Laranjo, Bernier, \& Meins, 2008). While there is a burgeoning literature on the beneficial impact of maternal mind-mindedness on children's development and its links with secure attachment relationships (Arnott \& Meins, 2007; Lundy 2003; Meins et al., 2012), understanding of the nature of the construct is still developing.

Mind-mindedness was originally operationalised (Meins et al.,1998) using a measure designed to access the representations in their simplest form by asking an interview question allowing the mother to provide a description of the child from which the proportion of the child's mental attributes mentioned were assessed. The later operationalisation, an interactional measure, was designed to assess mind-mindedness during an observational assessment in the child's first year. A mother is observed interacting with her child, with the coding of this focusing on a mother's tendency to refer to a child's internal states (Meins et al., 2001). A distinction can be drawn between mind-related comments that are appropriate or non-attuned. Making these mind-related comments relies on both having a representation of the individual and expressing that representation through some form of overt behaviour. The interview measure of mind-mindedness is an offline measure, not influenced by concurrent interaction whilst the interactional measure is online and open to influence from the immediate interaction (Arnott \& Meins, 2007; Lundy, 2013). Both measures are representational in that they call on the mother's conceptualisation of her child's internal 
states but the interactional measure draws on representational and behavioural facets of the caregiver's relationship with the child as these are used in the "here and now".

Mind-mindedness has been treated as an overarching construct but there is little research evidence supporting mothers' representational mind-mindedness as being related to their interactional mind-mindedness; studies tending to use only one of the measures. Two studies have used a representational and an interactional measure but based on their findings, it is not possible to state unequivocally that the two measures are convergent (Arnott $\&$ Meins, 2008; Meins et al., 2003) due to the design of the studies. Meins and colleagues (2003) found mothers' mind-mindedness when interacting with their 6-month-olds was positively related to their tendency to describe their children with reference to mental attributes at 4-years-old. However, the fact that the two approaches to assessing mindmindedness were used over two widely separated time points limits the strength of any claim to convergent validity because it is not possible to know whether mothers' mind-mindedness changed over time and whether or not any change may have accounted for the relationship between the measures. Arnott and Meins (2008) addressed whether mothers' ante- and postnatal mind-mindedness were associated. The total number of comments made in antenatal imaginings of their as yet unborn child (regardless of whether or not they made reference to mental attributes) was positively related to postnatal mind-mindedness assessed during mother-child interaction at 6 months. However, the standard index of representational mind-mindedness, that of mental attributes, was not related to interactional mind-mindedness, suggesting that the measures were not unequivocally related.

Mind-mindedness has been described as a cognitive-behavioural trait (Meins, Fernyhough, Arnott, Turner, \& Leekam, 2011) and as a relational construct (Arnott \& Meins, 2007; Meins et al., 2011; Meins, Fernyhough, \& Harris-Waller, 2014). A trait conceptualisation implies consistency in an individual's responses to different situations, 
allowing one to predict how a person will behave in the future. If maternal mind-mindedness is primarily a cognitive-behavioural trait, it should be reasonably stable across time. Meins and colleagues (2011) investigated mothers' tendency to comment both appropriately and in a non-attuned manner with infants firstly at 3 months and later at 7 months. They found a degree of stability but this was only over a 4-month period. While useful potential evidence, such a relatively brief period may not allow much time for maternal representations to change. A longer period between repeated measures (i.e. both observational or both interview-based) would better establish the stability of mind-mindedness.

The alternative conceptualisation of mind-mindedness is that it is primarily a relational construct. This implies a uniqueness to each relationship with maternal mindmindedness governed by the specific relationship. Mind-mindedness has been investigated as a possible mechanism whereby attachment quality is transmitted across generations (Arnott \& Meins, 2007). Measures of attachment quality derived from the Strange Situation (Ainsworth \& Wittig, 1969) in childhood are usually seen as relationship specific, reflecting the quality of an infant's relationship with its caregivers (Sroufe, 1985). The findings that a child's attachment to one parent need not echo their attachment to the other parent underlines this relationship specificity (Fox, Kimmerly, \& Schafer, 1991). Mind-mindedness can be argued to be similar, being both determined by the relationship (parent with child) but also potentially differing depending on the child in question, i.e. being dependent on the relationship and interaction with that specific individual rather than by some more general feature of "being a mother". It is possible that maternal mind-mindedness about siblings will be concordant but if this is the case then it would suggest that relationship specificity, in this context, is more about being a mother than about the relationship with each child.

Comparisons across relationships to date have only compared mothers' mind-mindedness in relation to a child and her partner. Meins et al. (2014) found that mothers' mind-minded 
descriptions of their child positively correlated with those they made of their romantic partner. The authors argued that this was consistent with mind-mindedness being both traitlike and a construct specific to close relationships because a mother's relationship with a child and a partner could be considered comparable in terms of intimacy. Currently, there is no evidence about the extent to which maternal mind-mindedness shows this specificity across relationships with more than one child. One possible test of relationship specificity would be to investigate mind-mindedness in relation to own child and another child with whom the mother has no established relationship. However, the differences in intimacy level and knowledge of the child might make such an approach difficult to interpret without first establishing whether there is concordance in mind-mindedness about siblings.

To extend our understanding of how mind-mindedness is expressed in interaction, we focused on mothers with preschool and primary school age children rather than infants. While the interview-based measure of mind-mindedness has been used in relation to children of widely different ages, the interactional measure was developed for use with pre-speech infants. One extension of the interactional measure to older children has been made to date. Lundy (2013) investigated parental scaffolding as a proxy for mind-mindedness in mothers with older children. She examined this in relation to a highly structured task which focused on the effectiveness and attunement of parental scaffolding of children's problem solving, finding a relationship between this modified interactional measure and the interview measure of mind-mindedness. The current study took a different approach to attunement with older children by investigating mind-mindedness in mother-child free play and focusing the extension of the measure on appropriate verbal references to internal states. The advantages of this approach are that free play reduces the constraints and motivational influences that a teaching task places on mothers while still permitting mothers to exhibit awareness of their child's internal states. Measurement of explicit internal state references in interactions 
between mothers and preschool children is well established in the literature (e.g., LaBounty, Wellman, Olson, Lagattuta, \& Liu, 2008). This approach also permits an examination of the relationship between explicit mind-related comments in interaction and mental attributions made in response to the mind-mindedness interview.

Much research that focuses on mind-mindedness as a potential contributor to subsequent development involves a considerable period between predictor and proposed outcome (Laranjo, Bernier, Meins, \& Carlson, 2010; Meins et al., 2003). The first aim of the current study was to assess the temporal stability of mind-mindedness as this has not yet been conclusively established. The second aim was to explore the consistency of maternal mindmindedness across relationships. The rationale for examining stability and consistency is to explore further whether mind-mindedness should best be seen as a cognitive-behavioural trait or a relational construct dependent on specific mother-child relationships. If maternal mindmindedness in relation to siblings is uncorrelated, this would undercut the idea that mindmindedness is influenced by a cognitive-behavioural trait. The implications of high correlations are less clear but would provide support, though not confirmation, for it as a trait-like quality. This entirely novel aspect of the design involved assessing maternal mindmindedness in relation to two children, allowing comparisons across individual relationships with similar dependency and intimacy. Mothers were also asked to describe their partner/close friend so that comparisons could be made between representational mindmindedness in relationships that are intimate, but of a very different nature.

A further aim was to investigate the relationship between the two operationalisations of the construct (mind-mindedness expressed through explicit references to internal states in mother-child interactions and in descriptions of children) and to do this concurrently and longitudinally. Given the exploratory nature of the research, no directional hypotheses were made. 


\section{Method}

\section{Participants}

Participants were 32 families from Oxfordshire. The mothers were predominantly educated to university level (87.5\%) and from high socio-economic status households (75\% in the two highest occupational categories assessed by the Standard Occupational Classification 2000). All mothers were English-speaking, with four mothers speaking English fluently as a second language. At Time 1, mothers' age ranged from 24 to 45 years $(M=38.63$ years $)$. The older siblings (19 boys, 13 girls) were aged between 4,10 years and 9,5 years ( $M=6,3$ years). The younger siblings (19 boys, 13 girls) were aged between 2,7 years and 6,4 years $(M=4$ years). The period between Time 1 and Time 2 visits was approximately 9 months $(M$ in weeks $=$ 38.50 , range 35 to 43 weeks). Sample attrition was minimal: only 2 of the 32 participating at Time 1 dropped out at Time 2.

\section{Procedure}

Data were collected in participants' homes and the same measures were used at both time points. Representational mind-mindedness was assessed, followed by interactional mindmindedness. Whether the older or younger sibling was described/played with first or second was counterbalanced both within and between time points.

\section{Measures}

Representational measure of mind-mindedness (Meins et al., 1998)

Mothers were asked the question: "Can you describe [name] for me?" Mothers described their children separately before they described their partner or close friend. Descriptions were 
audio recorded, transcribed and coded. All mothers who had partners chose to describe the partner; only two mothers at Time 1 and one mother at Time 2 described a close friend.

The coding of transcripts followed Meins and Fernyhough (2010). Each attribute was placed into one of four exhaustive and mutually exclusive categories: (a) Mental: References to the individual's mental life relating to will, mind, intellect, knowledge (e.g., "clever", “curious”). (b) Behavioural: References to behaviour, for example, individuals' activities and interactions with other people on a behavioural level (e.g., "he makes jokes all the time"). (c) Physical: References to physical appearance, age or position in the family (e.g., "she has curly hair”); (d) General: References that do not fit into the preceding three categories (e.g., “he's just great").

\section{Interactional measure of mind-mindedness (Meins et al., 2001)}

The measure was based on a 15-minute, free play session using a set of toys supplied by the researcher. The children chose from toys selected to appeal to a range of ages (e.g., tea set, Playmobil playground, magnetic construction toy). The mother-child play session was filmed separately for each child, transcribed and coded. The interactional measure, devised to be used with infants up to the age of 12 months, was adapted for an older age group after piloting with three mothers and their children. A more extensive coding manual, used in addition to Meins and Fernyhough's (2010) coding scheme, was designed to provide examples of categories of utterances and appropriate and non-attuned mind-related comments that were age appropriate. The child's use of language and greater comprehension necessitated these additions.

Mind-related comments were identified in the transcripts. These included comments referring to the child's desires and preferences, cognitions, emotions and epistemic states. When deciding whether comments were mind-related, examples of age-appropriate 
adaptation were: (a) If the mother repeated the child's speech containing a mental state term, this was not thought to be an example of a mother spontaneously considering her child's internal state and so was not coded as mind-related (e.g., Child: "I want to do a train track." Mother: "You want to do a train track, ok." ; (b) "Want" was sometimes used in the same way as "need" when instructions were being given and in this case was considered not to be referring to mental processes/desires of the child and was not coded as mind-related (e.g., When giving instructions for building a toy: "So you want to put this one in before you do the other bit.”); (c) Some mind-related comments were more likely to be included in mothers' speech to preschool and primary school children than to infants. (e.g., "Have you decided if they're going to go forwards or backwards?"; "You might have to imagine that there's an engine inside here."; “I need to use a different colour, do you mind?”).

After mind-related comments were identified, they were coded dichotomously as appropriate or non-attuned using the video of the interaction. Mind-related comments were deemed appropriate if these met at least one of the following criteria: (a) the coder agreed with the mother's interpretation of the child's internal state; (b) the comment linked the child's current activity with similar events in the past or future; or, (c) the comment clarified how to proceed after a lull in the interaction. Mind-related comments were coded as nonattuned if these did not meet the previous criteria and these decisions were highly context dependent. When deciding whether comments were appropriate, examples of adaptation for older children were: (a) It was not expected that the mother would always focus on what the child was doing to the exclusion of participating in the play session herself. When the mother asked the child whether they wanted to become involved in a new activity and the child was already actively playing, this was coded as appropriate or non-attuned depending on the particular instance. For example, when mother and child were playing with different toys, and the mother asked the child a question about her own toy, this was coded as appropriate (e.g., 
When mother was building a train track and asked: "Do you think that works?"); (b) Mindrelated comments were coded as appropriate even if a child responded with a "no" to the mother's comment if it appeared appropriate to the observer (e.g., Mother: "You think the bike might blow over?" Child: "No.”); (c) The majority of non-attuned comments occurred when a mother was either not attuned to her child's focus on/enjoyment of a particular toy or when a mother appeared to have her own agenda for play. For example, when the child was actively engaged in playing with a toy and it appeared the mother wanted to play with another toy (e.g., Mother: "Shall we do something else?" Child: "No." Mother: "Don't you want to try the puzzles?" Child: "No.").

\section{Mind-mindedness scoring}

Proportional scores controlling for differences in verbosity were calculated for representational mind-mindedness (mental attributes divided by total attributes produced by the mother) and interactional mind-mindedness (appropriate and non-attuned mind-related comments, each separately divided by total comments produced by the mother). Higher scores for appropriate mind-related comments are indicative of greater mind-mindedness. Inter-rater reliability was based on $25 \%$ of the interviews and interactions. Reliability for representational mind-mindedness was $k=.80$ for children and $k=.81$ for partners/friends while interactional mind-mindedness was $k=1$ for identification of mind-related comments and appropriate/non-attuned classification. Due to the small number of non-attuned mindrelated comments, the researcher showed these recordings to a second, trained rater and any disagreements were resolved by discussion.

\section{Results}

\section{Descriptive statistics and preliminary analyses}


The descriptive statistics are presented for Time 1 and Time 2 in Table 1. Mind-mindedness scores were normally distributed. Few mothers made any non-attuned mind-related comments, with two being the maximum number made by any mother. As a result, this variable was dropped from the analysis. The socio-demographic variables relating to the mother (age, education and socio-economic status assessed by household occupation) and to the child (age) were not normally distributed, therefore non-parametric correlations were carried out with these variables. Spearman's rho correlations indicated that mothers' representational and interactional mind-mindedness were unrelated to mothers' age, education and socio-economic status $\left(r_{s}<.35, p>.05\right)$ and to child age $\left(r_{s}<.30, p>.11\right)$. Independent samples $t$-tests were used to investigate potential group differences. To check for the possibility that mothers treat siblings more similarly when they are closer in age than when they are further apart, mothers were grouped according to mean sibling age difference in months $(M=27.66, S D=11.65)$ into a group with either a larger $(n=18$; greater than 27 months) or smaller ( $n=14$; less than 27 months) age difference. There were no significant differences in representational or interactional mind-mindedness by sibling age gap $(t \mathrm{~s}<$ $1.94, p s>.06)$. To explore potential child age effects on mothers' mind-mindedness further, associations between the difference in representational mind-mindedness scores (T1: $M=$ $6.06, S D=24.06$; $\mathrm{T} 2: M=3.0, S D=16.74)$ and the difference in interactional mindmindedness scores $(\mathrm{T} 1: M=0.54, S D=2.89 ; \mathrm{T} 2: M=1.82, S D=3.54)$ for older and younger siblings and age gap in months were calculated. No significant correlations were found $(r \mathrm{~s}<-$ $.22, p s>.23)$. Mothers' mind-mindedness did not significantly differ with gender for older or younger siblings $(t \mathrm{~s}<1.66, p \mathrm{~s}>.11)$. There were no order effects for the mind-mindedness interviews $(t \mathrm{~s}<1.89, p \mathrm{~s}>.07)$ or the play sessions $(t \mathrm{~s}<1.07, p \mathrm{~s}>.29)$. 
Table 1. Descriptive statistics for mothers' representational mind-mindedness (mental attributes) and interactional mind-mindedness (appropriate/non-attuned mind-related comments) at Time 1 and Time 2

\begin{tabular}{|c|c|c|c|}
\hline \multirow[t]{4}{*}{ Proportional scores (\%) } & Mothers using & Mean (SD) & Min-Max \\
\hline & mental attributes & & \\
\hline & or mind-related & & \\
\hline & comments & & \\
\hline
\end{tabular}

\begin{tabular}{|c|c|c|c|}
\hline \multicolumn{4}{|l|}{ Time $1(N=32)$} \\
\hline Older sibling: Mental attributes & 32 & $37.05(16.47)$ & $8.33-75$ \\
\hline Younger sibling: Mental attributes & 27 & $31.00(18.59)$ & $0-66.67$ \\
\hline Partner/friend: Mental attributes & 29 & $32.78(16.85)$ & $0-58.82$ \\
\hline Older sibling: AMRC & 32 & $6.00(3.30)$ & $1.35-14.43$ \\
\hline Younger sibling: AMRC & 32 & $6.54(3.11)$ & $2.04-12.70$ \\
\hline Older sibling: NAMRC & 9 & $0.17(0.30)$ & $0-1.17$ \\
\hline Younger sibling: NAMRC & 5 & $0.07(0.17)$ & $0-0.53$ \\
\hline \multicolumn{4}{|l|}{ Time $2(N=30)$} \\
\hline Older sibling: Mental attributes & 30 & $35.11(12.80)$ & $14.29-62.50$ \\
\hline Younger sibling: Mental attributes & 29 & $32.12(16.39)$ & $0-75.00$ \\
\hline Partner/friend: Mental attributes & 27 & $28.67(19.88)$ & $0-71.43$ \\
\hline Older sibling: AMRC & 30 & $5.52(2.72)$ & $0.90-11.63$ \\
\hline Younger sibling: AMRC & 29 & $7.34(4.12)$ & $0-15.00$ \\
\hline Older sibling: NAMRC & 7 & $0.20(0.47)$ & $0-2.08$ \\
\hline Younger sibling: NAMRC & 1 & $0.01(0.07)$ & $0-0.38$ \\
\hline
\end{tabular}

Note. AMRC $=$ appropriate mind-related comments; NAMRC $=$ non-attuned mindrelated comments. 


\section{Representational mind-mindedness: Concurrent relations between older sibling, younger}

\section{sibling and partner/friend}

As shown in Table 2, no significant correlations were found at Time 1. However, at Time 2 mothers' representational mind-mindedness, indexed by the proportion of mental attributes given in a description, showed positive correlations between younger siblings and older siblings, and between younger siblings and partners/friends.

Table 2. Correlations (Pearson's $r$ ) between mothers' representational mind-mindedness (mental attributes) with older sibling, younger sibling and partner/friend at Time 1 and Time 2

\begin{tabular}{lccc}
\hline Variable & Mental & Mental attribute & Mental attribute \\
& attribute & (Younger & (Partner/friend) \\
& (Older sibling) & sibling) & \\
\hline Mental attribute (Older sibling) & - & $.36^{*}(\mathrm{~T} 2)$ & $.30(\mathrm{~T} 2)$ \\
Mental attribute (Younger & $.06(\mathrm{~T} 1)$ & - & $.48^{* *}(\mathrm{~T} 2)$ \\
sibling) & & & \\
Mental attribute (Partner/friend) & $-.24(\mathrm{~T} 1)$ & $.08(\mathrm{~T} 1)$ & - \\
& & & \\
\hline
\end{tabular}

Note. $\mathrm{T} 1=$ Time $1 ; \mathrm{T} 2=$ Time 2.

$* p<.05 . * * p<.01$. 


\section{Interactional mind-mindedness: Concurrent relations between older sibling and younger} sibling

A rather different pattern of results emerged for interactional mind-mindedness. Mothers' interactional mind-mindedness, indexed by the proportion of appropriate mind-related comments made by a mother in a play session with a child, showed a significant positive correlation between older siblings and younger siblings with a large effect size (Cohen, 1988) at Time $1(r=.59, p<.001)$ and at Time $2(r=.53, p=.003)$.

\section{Temporal stability in mothers' mind-mindedness}

The temporal stability of mothers' mind-mindedness across a nine month period was investigated. Positive correlations showing temporal stability were found with mothers' representational mind-mindedness for the older sibling $(r=.47, p=.009)$, for the partner/friend $(r=.47, p=.009)$ and for younger siblings a strong trend towards significance $(r=.36, p=.051)$. Mother's interactional mind-mindedness was robustly positively correlated across time with older siblings $(r=.46, p=.01)$ and younger siblings $(r=.71, p<$ $.001)$.

\section{Relations between representational and interactional mind-mindedness}

To investigate the convergent validity of the two operationalisations of maternal mindmindedness, relations between representational and interactional mind-mindedness scores for each child were explored. There were no significant relations for the older sibling $(r=.03, p$ $=.87)$ or for the younger sibling $(r=-.13, p=.48)$ at Time 1 , with the pattern being repeated at Time 2 for both older sibling $(r=-.26, p=.16)$ and younger sibling $(r=-.15, p=.43)$.

Having established that the measures were concurrently unrelated, longitudinal relations between the measures were explored. Mothers' representational mind-mindedness at 
Time 1 and interactional mind-mindedness at Time 2 were not significantly related for the older sibling $(r=-.21, p=.28)$ or for the younger sibling $(r=-.22, p=.24)$. Interactional mind-mindedness at Time 1 and representational mind-mindedness at Time 2 were also not significantly related for the older sibling $(r=-.18, p=.33)$ or for the younger sibling $(r=-$ $.22, p=.24)$.

\section{Discussion}

The first aim of the study reported here was to establish whether or not mind-mindedness was stable across time. Strong evidence was provided for stability in mothers' representational mind-mindedness for both their children and their partner/friend. For interactional mindmindedness, the results suggest an impressive stability in mothers' appropriate references to their children's internal states in interactions for both older and younger siblings. For the first time, therefore, stability in mothers' mind-mindedness has been demonstrated with preschool and primary school children. The study provided even more compelling evidence for continuity across time than previously found in relation to infants (Meins et al., 2011) for two reasons. Firstly, mothers' interactional mind-mindedness was found to be stable with not just one, but with two children. Secondly, the timescale involved was longer, with the period of time between measurement of mind-mindedness being nine months as opposed to four months; consequently more confidence can be placed in the evidence from this study for temporal stability than that provided by the previous research.

Most theorists have suggested that the trait model is supported by evidence of longitudinal stability (Funder, 1991; McRae \& Costa, 2003). The finding of stability across time in maternal representational and interactional mind-mindedness could be interpreted as strengthening the view of mind-mindedness as a trait in the mother. Alternatively, the stability of the mother-child relationship over time may be responsible in itself for the 
stability of mind-mindedness. Our design cannot fully rule out this suggestion. While nonsignificant correlations relating to the same child over time would have undercut the trait argument, positive results leave it open to interpretation. However, the stability found in mothers' mind-mindedness with children of different ages is impressive. It suggests that maternal mind-mindedness is not a transient phenomenon but one that shows considerable continuity in relation to children of varying ages in the preschool and primary school years.

The second aim was to examine the potential consistency of mind-mindedness across relationships. Establishing consistency concerning different individuals would also provide support, though not confirmation, of it being a trait-like quality. In contrast, lack of consistency across relationships may suggest mind-mindedness is a relational construct tied to a specific individual, i.e. being relational at the micro rather than macro level. At Time 1, there was no support for consistency of representational mind-mindedness between relationships. However, at Time 2 there was evidence of consistency for mind-mindedness about older and younger siblings, as well as for younger sibling and partner/friend, the latter in line with Meins et al. (2014), but not for older sibling and partner/friend. Given the relatively small sample size, interpretation of these findings needs to be cautious. The conservative interpretation is that the lack of systematic pattern is more supportive of representational mind-mindedness as a specific relational construct than a cognitivebehavioural trait.

Clear-cut findings emerged regarding relations between mothers' interactional mindmindedness with their two children. Mothers' verbal behaviour was very similar irrespective of which child was taking part in an interaction. The strength and consistency of this finding is bolstered by the large and almost identical effect sizes found at each time point and because these associations were found at two time points, nine months apart. This suggests that while mothers might talk differently about their children, they interact with them in very 
similar ways in terms of appropriate mind-related language. This provides support for our measure of interactional mind-mindedness as a cognitive-behavioural trait in the mother. However, given that the mother is likely to have a close relationship with both children, this consistency could also be argued to support the view that interactional mind-mindedness is a relational construct. Comparisons of mothers' interactions with their own children and other children with whom they have less intimate connections (e.g., a friend's child) would allow a stronger case to be made for the trait view and go some way towards settling the question of whether it is the nature of adult-child interactions in general rather than the relationships between the participants that drives mind-mindedness.

The lack of a significant relationship between mothers' representational mindmindedness and interactional mind-mindedness for each child, not only concurrently but also longitudinally, is surprising. These results present a slightly different picture to that presented by Meins et al.'s (2003) study where a longitudinal relationship between early interactional and later representational mind-mindedness was found. One possible explanation for this difference is the age of the children in our study (i.e. preschoolers and primary school age rather than the infants and pre-schoolers investigated by Meins et al.). While mothers' interaction with infants and older children differs in many respects, the proportion of appropriate mind-related comments made by mothers in this study was similar to those reported in other studies (Meins et al., 2003, 2011. Arguably, a mother faces a greater challenge to be in tune with a pre-verbal infant's internal states. For a mother to be mindminded in interactions with her infant, more "mind-reading" might be required than with an older child with clear expressive language skills and more transparent thoughts and emotions. However, it is important not to equate transparency of internal states with children's ability to express themselves verbally. Even when internal states can be inferred from a wider range of behaviours, the very nature of internal states involves a degree of opacity and therefore is 
dependent on context for interpretation. This potentially age-related variability in the level of difficulty in being attuned to a child could well influence the relations between a mother's interactional and representational mind-mindedness.

Our findings also differ from Lundy (2013) who reported a link between representational mind-mindedness and an interactional measure that could be considered an investigation into attunement of parental scaffolding. Lundy argued that for older children, parental attunement was manifested in appropriate interventions in a problem-solving task. The rationale was that mind-minded parents would "continuously monitor their child's mental processes throughout the task, modifying their level of interventions accordingly" ( $\mathrm{p}$. 61). However, our interactional measure focused on appropriate references to internal states in play sessions, thus remaining closer to Meins and colleagues' (2001) original measure, which may explain the discrepancy with Lundy's findings. Future research should investigate how measures of scaffolding and appropriate mind-related comments are associated.

The implications of these findings, albeit preliminary, are important because mindmindedness has been treated in the literature as an overarching construct, operationalised in two different ways. The failure to find an association in the data reported here suggests that these operationalisations may not measure exactly the same construct in mothers with older children. Mind-mindedness has been referred to as multidimensional, on the basis of findings that appropriate and non-attuned mind-related comments make independent contributions to attachment (Meins et al., 2012). It is possible that representational and interactional mindmindedness further demonstrate the complexities of this construct. Why were mothers' representations of a child's internal states in their descriptions not related to their verbal references to the child's mind in the play sessions? One possible explanation is that, as argued by Arnott and Meins (2007), the representations which inform mothers' mind-related comments in interactions are themselves grounded in online, real life interactions; in other 
words, representations and behaviour inform each other. It is not just the language which the mother uses but also the interplay between two individuals which affects interactional mindmindedness.

A clear difference between the operationalisations is that representational mindmindedness draws on offline representations and these may not be identical to the current, online representations accessed by mothers whilst interacting with their child. Additionally, it could be proposed that mothers may make use of prospective representations of their child in interactions - what the child is likely to feel or think in the future - based on prior knowledge and experience of that child and that this in turn influences mind-mindedness. This more complex use of representations in interactions may have contributed to the failure to find a relationship between the operationalisations.

If, as suggested by this study, maternal representational and interactional mindmindedness may not be interchangeable, it may be important to distinguish between them in future research. The two operationalisations might even have different implications for children's development. A great deal of evidence has been found in support of early interactional mind-mindedness as a precursor of child development associated with positive outcomes, for example, secure attachment relationships (Arnott \& Meins, 2007; Lundy, 2003; Meins et al., 2012), children's superior mentalising abilities (Laranjo et al., 2010; Meins et al., 2003), and a reduced tendency to later rate their child's behaviour as difficult in low SES families (Meins, Munoz Centifanti, Fernyhough, \& Fishburn, 2013). Establishing relationships between interactional mind-mindedness for older children and their social development would be a useful focus for future research. The beneficial influence of representational mind-mindedness for a mother-child relationship is less well documented. Exploration of the difference between representational and interactional mind-mindedness 
needs to establish whether associations with child outcomes vary for the two operationalisations.

The results of the current study should be considered as preliminary in the light of sample limitations. The sample size was relatively small and replication with a larger sample would be desirable. Although maternal mind-mindedness was not found to be associated with child age or sibling age gap, we do not rule out the possibility that mind-mindedness might be affected by child age. Replication in future studies with children closer in age would allow more confidence to be placed in the findings. A further issue relates to the homogeneity of the sample; the mothers were predominantly highly educated and from high socio-economic households. It is possible that this lack of diversity reduces the generalisability of the findings. However, mind-mindedness has generally not been found to relate to SES or mothers' education (Meins et al., 1998, 2011; Walker, Wheatcroft, \& Camic, 2011). The inclusion of at-risk or disadvantaged populations would allow an investigation into whether the longitudinal stability found with the current community sample holds true for other groups.

This study was the first to examine maternal mind-mindedness in relation to two children. It provides initial evidence of the temporal stability of both representational and interactional mind-mindedness in relation to preschool and primary school children. However, only interactional mind-mindedness showed consistency across relationships (i.e. for both siblings) and this finding may therefore be more supportive of interactional mindmindedness as a trait rather than a relational construct. Representational and interactional mind-mindedness were unrelated concurrently and across time, suggesting that mindmindedness, assessed by interview and observation, is worthy of further investigation in relation to preschool and primary school children. 


\section{References}

Ainsworth, M. D. S., \& Wittig, B. A. (1969). Attachment and exploratory behaviour of oneyear-olds in a strange situation. In B. M. Foss (Ed.), Determinants of Infant Behaviour, Vol. 4, (pp. 113-136). London: Methuen.

Arnott, B., \& Meins, E. (2007). Links among antenatal attachment representations, postnatal mind-mindedness and infant attachment security. Bulletin of the Menninger Clinic, 17, 132-149. doi:10.1521/bumc.2007.71.2.132

Arnott, B., \& Meins, E. (2008). Continuity in mind-mindedness from pregnancy to the first year of life. Infant Behavior \& Development, 31, 647-654.

doi:10.1016/j.infbeh.2008.07.001

Cohen, J. (1988). Statistical power analysis for the behavioral sciences. Hillsdale, NJ: Lawrence Erlbaum Associates.

Fox, N. A., Kimmerly, N. L., \& Schafer, W. D. (1991), Attachment to mother/Attachment to father: A meta-analysis. Child Development, 62, 210-225. doi: 10.1111/j.14678624.1991.tb01526.x

Funder, D. C. (1991). Global traits: A neo-Allportian approach to personality. Psychological Science, 2, 31-39.

LaBounty, J., Wellman, H. M., Olson, S., Lagattuta, K., \& Liu, D. (2008). Mothers' and fathers' use of internal state talk with their young children. Social Development, 17, 757-775. doi: 10.1111/j.1467-9507.2007.00450.x

Laranjo, J., Bernier, A., \& Meins, E. (2008). Associations between maternal mindmindedness and infant attachment security: Investigating the mediating role of maternal sensitivity. Infant Behavior and Development, 31, 688-695. doi:10.1016/j.infbeh.2008.04.008 
Laranjo, J., Bernier, A., Meins, E., \& Carlson, S. M. (2010). Early manifestations of children's theory of mind: The roles of maternal mind-mindedness and infant security of attachment. Infancy, 15, 300-323. doi:10.1111/j.1532-7078.2009.00014.x

Lundy, B. L. (2003). Father- and mother-infant face-to-face interactions: Differences in mind-related comments and infant attachment? Infant Behavior and Development, 26, 200-212. doi:10.1016/S0163-6383(03)00017-1

Lundy, B. L. (2013). Paternal and maternal mind-mindedness and preschoolers' theory of mind: The mediating role of interactional attunement. Social Development, 22, 58-74. doi:10.1111/sode.12009

McCrae, R. R., \& Costa, P. T. Jr. (2003). Personality in adulthood: A five-factor theory perspective ( $2^{\text {nd }}$ edition). New York: Guilford.

Meins, E. \& Fernyhough, C. (2010). Mind-mindedness Coding Manual, Version 2.0. Unpublished manuscript. Durham University, Durham, UK.

Meins, E., Fernyhough, C., Arnott, B., Turner, M., \& Leekam, S. (2011). Mother- versus infant-centered correlates of maternal mind-mindedness in the first year of life. Infancy, 16, 137-165. doi:10.1111/j.1532-7078.2010.00039.x

Meins, E., Fernyhough, C., de Rosnay, M., Arnott, B., Leekam, S. R., \& Turner, M. (2012). Mind-mindedness as a multidimensional construct: Appropriate and nonattuned mindrelated comments independently predict infant-mother attachment in a socially diverse sample. Infancy, 17, 393-415. doi:10.1111/j.1532-7078.2011.00087.x

Meins, E., Fernyhough, C., Fradley, E., \& Tuckey, M. (2001). Rethinking maternal sensitivity: Mothers' comments on infants' mental processes predict security of attachment at 12 months. Journal of Child Psychology and Psychiatry, 42, 637-648. doi:10.1111/1469-7610.00759 
Meins, E., Fernyhough, C., \& Harris-Waller, J. (2014). Is mind-mindedness trait-like or a quality of close relationships? Evidence from descriptions of significant others, famous people, and works of art. Cognition, 130, 417-427. doi:10.1016/j.cognition.2013.11.009

Meins, E., Fernyhough, C., Russell, J., \& Clark-Carter, D. (1998). Security of attachment as a predictor of symbolic and mentalising abilities: A longitudinal study. Social Development, 7, 1-24. doi:10.1111/1467-9507.00047

Meins E., Fernyhough C., Wainwright R., Clark-Carter D., Das Gupta M., Fradley E., \& Tuckey, M. (2003). Pathways to understanding mind: Construct validity and predictive validity of maternal mind-mindedness. Child Development, 74, 1194-1211. doi:10.1111/1467-8624.00601

Meins, E., Harris-Waller, J., \& Lloyd, A. (2008). Understanding alexithymia: Associations with peer attachment style and mind-mindedness. Personality and Individual Differences, 45, 146-152. doi:10.1016/j.paid.2008.03.013

Meins, E., Munoz Centifanti, L. C., Fernyhough, C., \& Fishburn, S. (2013). Maternal mindmindedness and children's behavioral difficulties: Mitigating the impact of low socioeconomic status. Journal of Abnormal Child Psychology, 41, 543-553. doi:10.1007/s10802-012-9699-3

Sroufe, L. A. (1985). Attachment classification from the perspective of infant-caregiver relationships and infant temperament. Child Development, 56, 1-14.

Standard Occupational Classification 2000 (SOC 2000) Volume 1. Retrieved from Office for National Statistics website: http://www.ons.gov.uk

Walker, T. M., Wheatcroft, R., \& Camic, P. M. (2011). Mind-mindedness in parents of preschoolers: A comparison between clinical and community samples. Clinical Child Psychology and Psychiatry, 17, 318-335. doi:10.1177/1359104511409142 